Note: The below essay is roughly identical to the version published in Rethinking Marxism 8(2) Summer 1995. A modified version is also in my dissertation; and an earlier draft was presented as "Some Remarks on Racism and Nationalism," delivered at the Marxism in the New World Order Conference, November 12-14, 1992.

\title{
The Racial Other in Nationalist Subjectivations: A Lacanian Analysis
}

\author{
David Mertz \\ mertz@gnosis.cx
}

David Mertz is currently a Ph.D. candidate in the University of Massachusetts, Amherst, Philosophy Department [since awarded degree]. Within his work in "Ideology Critique," he is currently exploring hegemony formation in the post-Cold War era, around such condensations/displacements of class-antagonisms as the War on Drugs, and myths about AIDS.

Etienne Balibar [Balibar, 1991], in an article in New Left Review, entitled, "Es Gibt Keinen Staat in Europa: Racism and Politics in Europe Today" raises the question of the relation of the State to both racism and nationalism. The question in his paper is more specific than shall interest us in this essay - his particular interest is in the new forms of racism which are developing in Europe at this particular juncture - however, by focussing on a few of Balibar's remarks, and expanding them within the conceptual context laid out in Slavoj Žižek's magnificent book, The Sublime Object of Ideology [Žižek, 1989], we may be able fruitfully to address these issues of racism and nationalism at a general conceptual level.

At the level of abstraction at which this essay shall operate, we hope to identify a constellation of relations amongst racism, nationalism and State(ism) which hold common through most or all of the myriad forms of all three within the two hundred year horizon of their common existence. In the final section of this essay, we will attempt to show how the conceptual scheme which we develop out of Žižek and Balibar belie Benedict Anderson's severing of the relationship between nationalism and racism near the end of his otherwise profound and fundamental examination of nationalism, Imagined Communities [Anderson, 1983]. The central importance of such a critique of Anderson lies in his representativeness of many on the Left who believe it possible effectively to combat racism within a context of nationalism. The argument in the first part of this essay suggests that every political challenge which truly confronts racism - rather than simply altering its terms incrementally — must simultaneously confront the ideological forms of nationalism and statism.

Let us examine an illustrative remark made by Balibar,

In essence, modern racism is never simply a 'relationship to the Other' based upon perversion of cultural or sociological difference; it is a relationship to the Other mediated by the intervention of the state. Better still - and it is here that a fundamentally unconscious dimension needs to be conceptualized-it is a conflictual relationship to the state which is lived' distortedly and 'projected' as a relationship to the Other. [Balibar, 1991, 15]. 
These remarks by Balibar divide naturally into two parts: first, modern racism is a 'relationship to an Other based upon perversion of cultural difference'; second, modern racism is not this relationship simpliciter, but is rather 'mediated by the State'. The first of these parts is perhaps commonplace. And perhaps it is equally apparent that Balibar's first thesis (if I may call it such) is not adequate, that it requires a supplement-in the sense of a supplement as that which is necessarily, and essentially, excluded by the original part. Such a connection between the two theses is the argument of this essay; it is not a argument Balibar himself makes. That is, although racism is clearly a perversion of cultural differences with an Other, it presents itself as such precisely to mask its true nature which is something quite different from this.

Where Balibar suggests something interesting is with the phrase 'conflictual relationship to the State'. Let us look at a suggestion made in this regard Žižek. Žižek addresses a very particular racism in terms of its "societal" function, namely anti-semitism.

\begin{abstract}
'Society doesn't exist', and the Jew is its symptom. ... [T] [Te stake of social-ideological fantasy is to construct a vision of society which does exist, a society which is not split by an antagonistic division, a society in which the relation between its parts is organic, complementary. The clearest case is, of course, the corporatist vision of Society as an organic Whole. . . The 'Jew' is the means, for Fascism, of taking into account, of representing its own impossibility. ... [However,] far from being the positive cause of social antagonism, the 'Jew' is just the embodiment of a certain blockage — of the impossibility which prevents the society from achieving its full identity as a closed, homogeneous totality. Far from being the positive cause of social negativity, the 'Jew' is a point at which social negativity as such assumes positive existence. . Society is not prevented from achieving its full identity because of Jews: it is prevented by its own antagonistic nature, by its own immanent blockage, and it 'projects' this internal negativity into the figure of the 'Jew'. In other words, what is excluded from the Symbolic (from the frame of the corporatist socio-symbolic order) returns in the Real as a paranoid construction of the 'Jew'. [Žižek, 1989, 125-7]
\end{abstract}

What is going on in this excerpt from Žižek? The passage cannot be read "logically" insofar as it attributes to a non-being a definite attribute (a symptom). Society does not exist but society is retroactively created by its own symptom. This formula will be found suggestive of Laclau and Mouffe's use of the concept hegemony [Laclau and Mouffe, 1985], which also concerns retroactivity in the foundation of group-being, and from which Žižek acknowledgedly borrows much of his analysis. The 'Jew' is a symptom of society's anxiety over its own unity; but this unity only exists retroactively insofar as the 'Jew' functions as the disruption of this unity. An organic unity of society exists only in so much as this very organic unity projects onto some fictive figure of alterity its own immanent contradictions. The unity "exists" Symbolically, but not in the Real. Pay close heed to the paradoxical formulation of this projection: the notion of alterity formulated by Žižek radically contradicts the simple notion, also rejected by Balibar, of a simple loathing of cultural/racial differences. Rather, the very possibility of anti-semitism or other racisms presupposes the existence of society as an organic unity, but this organic unity is created only through the projection onto the 'Jew' (or onto some such figure) of the fantasy of Otherness.

The simple notion of loathing of cultural differences is naive precisely because it supposes that cultures exist independently of their exclusion of Otherness, that a culture may constitute itself as an entity without in the same act constituting the "cultures" it excludes from its own definition. In fact, these excluded "cultures" have logical precedence over the cultures which create them; not in the sense that an "included" group, in order to form its sense of self-identity, must have come in contact with a foreign group which had historically preceded the "included" group in constituting 
an identity-indeed, the process of identity construction retroactively creates an historical aboriginality of the interior group - but in the sense that the existence of the exterior group is conceptually necessary for defining the interior group.

An excluded exterior group - in respect to its function in the nationalist fantasy - is in no sense a concrete collection of people who, empirically, may or may not have the traits loathed by the interior group, but is precisely a fetishistic projection of the nullity of the interior group's existence. To be clear, according to our analysis the image created of alterity used retroactively to found identity has nothing whatsoever to do with the empirical traits of the groups excluded (the fact that the excluded group may indeed have the traits ascribed to it is quite simply irrelevant). In Poland, to choose an example, anti-semitism is becoming the unifying national identity of a nation unable to face the fact that the Capitalism being rapidly introduced into the country is precisely a system of schisms amongst "the people," a disunity of national identity. Jews—or rather 'the Jew'-become the projected site of disunity which allows "Poles" to maintain a fantasy of unity. What makes this situation's paradox particularly glaring is the fact that there are virtually no Jews in Poland.

According to my reading of Žižek, the "Jew" in anti-semitism occupies the same position as that indicated by the sign $S(\varnothing)$ in Lacanian theory and analysis - or rather, anti-semitism is the process of displacement from the position $S(\varnothing)$ to the "Jew." $S(\varnothing)$ is the sign which marks the impossibility at the core of the Symbolic order (marked by the capital 'Other'). Those familiar with Lacanian theory ${ }^{1}$ will realize that the use of the mark $S(\varnothing)$ for the anti-semites' "Jew" indicates another conclusion shared by Žižek: that racism is always tied to a surplus of enjoyment, the jouissance of a fantastic projection of a moment of subjectivity before subjectivation/castration. We have a fear of losing something we never "really" had-and it is precisely this fear which presupposes the existence of the object. This object grounds the Symbolic order, but signifies an impossibility or self-contradiction (a thing which only exists by virtue of the fear of its loss). But it is, in turn, only insofar as there exists this strangely grounded Symbolic order that we are able to situate ourselves within it and become Subject(ivated) within it. The role of fantasy is precisely to mask to the Subject the impossibility which grounds the Symbolic order within which she necessarily locates herself. To put this back in terms of the racist/nationalist complex about which we are talking, we may say, "If society could constitute itself as a real-empirical unity, it would not need the Jew."

\footnotetext{
${ }^{1}$ An excellent beginner's introduction to substantially all major aspects of Lacan's thought is Jonathan Scott Lee's Jacques Lacan [University of Massachusetts, 1991]. Žižek's Sublime Object of Ideology is a nice introductory text itself, although it does much more than just introduce Lacan's thought.

Lacan's project as a whole might be said to be a succession of efforts to ground the impossibility of the subject. Before all the later "postmodernists" who share his conclusion, and more radically than the many "antiCartesians" who precede him, Lacan performs a radical critique of Cartesian subjectivity, as a dictum for psychoanalytic practice. For Lacan, psychoanalysis starts with the non-Being of the subject, then slowly unravels the subject's pretensions to Being.

One of the blockages encountered in the Lacanian "unravelling" is the point at which the non-subject "blames" its non-Being on the non-Being of the Symbolic Order. The Symbolic Order is the common domain of communicative exchange in which the subject demands it be subjectivated. This $S(\varnothing)$ is merely one of several of what we might fancifully describe as 'roadblocks on the road from non-Being to non-Being'-but it is the important one for the conceptual analysis of the Racist/Nationalist complex at hand.
} 
Here we return to our initial question of the relation of the State to racism and to nationalism. Our use of Žižek has allowed us to claim that nationalism is a function of racism in the special sense that racism is the mask which allows a nationality to conceive itself. This does not seem to require the State to play any particular role in this "spirit of nationalism." But then we can not help notice that in the two hundred year history of "Nation-States," the State has always played a very marked and crucial role in every conception of nationality and nationalism. Indeed, for these last two hundred years there has been no "Nation" in Europe or in the sphere of European imperialism which did not at the same time have statist ambitions, and no "State" which did not have nationalist ambitions. To understand the brief history Nation-State's syncretic self-conception we will turn shortly to the recent book which, despite its recentness, defines this field of understanding - and to which both Žižek and Balibar acknowledge their debt—Benedict Anderson's Imagined Communities [Anderson, 1983].

\section{The Subject Supposed to Know}

Let us present a thesis which we believe is consistent with the spirit of Anderson's book, which attempts to insert Anderson's thinking into the framework given in Žižek which we have adopted. If, for nationalists, a racially alterior group holds the position of $S(\varnothing)$, then the State holds that of the Lacanian Subject Supposed to Know. If we can make a convincing case for these two positionings, then we will have succeeded in finding something like the kind of close relation between racism and the State which Balibar supposes to exist.

What is the "Subject-Supposed-to-Know?" The position of the Subject-Supposed-to-Know has a fantastic function; it is the Subject in whom we fantasize the ability to know the "truth" of subjectivity. In the classical psycho-analytic encounter the analyst comes to occupy just this position for the analysand, through transference; the analysand fantasizes that the analyst has found the true unconscious nature which underlies her symptoms. The Subject-Supposed-to-Know has a fantastic function because, as we have written, the function of fantasy is to mask the impossibility at the core of the Symbolic order-and the Subject-Supposed-to-Know's fantastic ability to know the "truth" of subjectivity allows the further fantasy that the Symbolic order (through location in which subjectivity is possible) has an essential core.

In the psychoanalytic encounter, there is a fundamental resistance to the "working through" of fantasy, because the end result of the full visibility of the structure of fantasy would be the disincorporation of the subject, who is only subjectivated within the fraud of the Symbolic Order. Transference is an attempt by an analysand to block the process of analysis. Whereas the inherent direction of the analytic encounter is to reveal the incoherency on which subjectivity is founded, transference onto the analyst acts as a stop-gap to this process by staking the claim that subjectivity must have a "truth" insofar as the analyst may know and reveal it. Similarly, we may speak of the subjectivity of a National Subject insofar as it becomes the State itself which acts as the stop-gap to the realization of the incoherency of any real-empirical national-identity.

The central claim of this essay is just the following: Whereas racially alterior groups are the object of displacement of the antagonism at the core of the national/Symbolic order for nationalists, the State functions for them as the Subject-Supposed-to-Know. For these explanations to make any sense at all, a trick of prestidigitation must have been performed. This trick, however, is not the blithe and unreflective equation of individual Subjects with "national subjects." The correct trick 
involves making nationality central to a subjectivity defined by the "natural" answer to the question, "What are you?" The history of this "trick" is the subject matter of Anderson's book.

It must become possible for people to say 'I am an American' (for example) with the same blind conviction and willful obliviousness to glaring absurdities as one says 'I am a man' (or, alternately, 'woman') — rather than with the kind of measured confidence and assurance with which one says 'I am a Marxist' or even 'I am a Christian'. But somehow, through conditions which were entirely historically contingent-almost accidental, in fact-over these last two hundred years the majority of living human beings have come to believe in nationality with just the conviction we have mentioned-what they are is members of a given nationality. If we talk about nationalism, racism and the State in the terms of the most basic processes of human psychic development, it is nonetheless with the knowledge that it is entirely contingent, and only recently, that we can talk this way-though none less accurate for that.

The State is, in some sense, composed of concrete individuals. But the State as a Symbolic function is of a fundamentally different order than the collection of individuals who compose it. Just as racism has nothing to do with the empirical properties of Symbolically exterior groups, what we might call 'Statism' has nothing to do with the empirical properties of the individuals who compose the State. Of course, the particular individuals who have or seek political power within (or over) States are quite likely to play off the racist and nationalist sentiments of a State's populace, in as jingoistic and as opportunistic manner as they are able. Of course, particular Capitalist do their utmost to divide the working class on racial lines in order to break unions, and to create situations of so-called "super-exploitation." Of course it is an empirical property of most politicians that they

\footnotetext{
${ }^{2}$ The absurdity here is, of course, the presupposition that one names any real-empirical trait with the claim of national-identity. A more accurate way of understanding a claim of national-identity is as a pure performative which stakes a claim to a particular enunciative position-but which has no referential meaning whatsoever. However, nationalist—not only fervent political nationalist, but the ordinary citizens who conceive themselves as nationals-inevitably insist that their claim to national-identity is a substantive statement which describes an independent real-empirical nature. The distinction between the claims of national-identity and those of political affiliation which I mention becomes clear when one poses a question of the conditions of knowledge of the different identities. With national-identity, it is possible to discover one was not what one thought-for example, by discovery of adoption into a family, or of other previously unknown circumstances surrounding one's birth (or even of one's parents' birth or blood). However, we cannot normally decide not to belong to our national-identity: we may reject the values, politics, religion, etc. of our nation, but still it is the values, et alia of our nation we reject. Just the opposite applies to a political/belief affiliation. It makes no sense to discover that we are not really Marxists (or Democrats, Tories, etc.), as we had thought—but it may be possible to convince us no longer to hold such beliefs (I leave aside such trivial possibilities as finding that one has forgotten payment of one's party dues, and hence are no longer technically a member of a given group). This is clearly because our political affiliations are better understood for what they are: performative claims to enunciative positions.

One of the most influential discussions of the performative nature of sexual/gender identities, in particular, is Judith Butler's Gender Trouble [Routledge, 1990]. She argues persuasively that there really is something rather absurd in our belief in genders. Ann Fausto-Sterling does likewise, in Myths of Gender [Basic Books, 1992], from the rather different perspective of a biologist. In any case, to claim these absurdities are "glaring" is hardly to claim they are widely noticed. Many things shine without being seen.
} 
actively increase the viciousness of the racism and nationalism within their "nation." But all of this misses the point in explaining the Statist function; just as much as does examining the actual properties of Jews in understanding anti-semitism (maybe they really do own the banks, and steal our children, and so on, but so what?). The banal facts that Capitalists are racists, and politicians Statists brings us no closer to understanding the centrality of race, nation, and State in subjectivity.

If we, as Subjects, have an essence — as is, indeed, demanded by our being as Subjects-we only have it as Subjects of something. The 'something' to which we are Subject(ivat)ed is generically, in the Lacanian language, the Symbolic order, i.e. the 'Paternal Law'; but this 'Paternal Law' is only spoken by a Subject-Supposed-to-Know, a Subject supposed to be able to speak the truth of the Subject. The Subject has an essence only insofar as this essence has been interpellated by the Subject-Supposed-to-Know, but the Subject-Supposed-to-Know exists only insofar as it can adequately (re)present the Subject. The Subject-Supposed-to-Know is 'in us more than we are in ourselves' since it is always onto-symbolically prior to the self, though only as a fiction of the self. In other words, in projecting onto an object the function of the Subject-Supposed-to-Know, the Subject retroactively creates what must have always already been at the core of the self.

All of this goes for the State. Insofar as subjectivity has become, in these last two hundred years, a National—or, perhaps better, Nationalized—subjectivity, the Subject-Supposed-to-Know which onto-symbolically grounds the Subject has become, at least in part, the State which onto-symbolically grounds the Nation. But, as we have written, the State may so ground the Nation only insofar as it also (re)presents the Nation, insofar as it speaks the truth of the Nation. Clearly it is not the essence of States, sui generis, to represent Nations - as the existence of pre-National dynastic States shows - but rather is an historical property of modern 'Nation-States'. Despite its historical recentness, the National form which modern States have taken has become the universal and necessary condition of their political legitimacy; and they have taken this form precisely insofar as National-Subjective entities have come into historical existence in relation to these States. We can see the retroactive creation by States of always already given Nations quite easily in the archaic pretensions of Nations. As just one of many examples we may notice that one of the first acts of the Swiss State, at the very eve of its creation as a political entity in 1891, was the decision of '1291 as the date of the "founding" of Switzerland' [Anderson, 1983, 123]. Although no surety exists of such decisions entering the "popular imagination" (or more precisely, the "popular Symbolic"), we can see factually that in a great many cases they have.

Let us turn, then, to Anderson's historical "reflections on the origin and spread of Nationalism" (these words make the subtitle of his book). Anderson's text is crucial for understanding the history of nationalism wherethrough subjectivity has become nationalized in the fashion we have suggested above. An anomaly has already been mentioned regarding Anderson: although the last topic ${ }^{3}$ Anderson addresses in his book is the relationship between Racism and Nationalism, he concludes that the two are unrelated. Yet our reading of his own text serves strongly to reinforce our belief in the connection we have been explicating. How can we explain our disagreement with Anderson? We believe that Anderson, despite his brilliant explication of the contingency and recentness of Nationalism, in the end-in a very subtle manner-actually winds up taking Nationalism's self-

\footnotetext{
${ }^{3}$ In the first edition - the second edition does not modify this conclusion, but only its position within the text.
} 
perception of necessity and archaity too seriously. Where Anderson notices the contingency of the historical construction of Nationalities, he fails to notice their continuing contingency at every moment of their existence; where he recognizes the creation of Nationality as mere machinations of States, he still supposes that this creation comes to exist at the level of reality as opposed to that of Symbolic fantasy.

\section{Anderson's Imagined Communities}

The single most important historical precondition for the development of the Racial/National complex we analyze has been the evolution of a particular conception of time. The notion of simultaneity is the conceptual forerunner of nationalists' notions of the commonality or identity between national subjects. Time, like any cultural meaning has a particular history and genealogy; and in these last few hundred years, the history of time has been the history of Nationalism. In order to understand how time has changed, it's useful to trace the associated development of Nationalism.

Anderson breaks the development of Nationalism into three stages, corresponding not only to the historical sequence in which they have arisen, but also to the differing political and technological circumstances which make them possible. In all cases an imagined community which corresponds to certain real potentials for communication and interaction forms the basis of what becomes a Nation. In the first two stages, the existence or creation of a common vernacular across the imagined community plays a central role; in the third stage, both because of the newer technological supersession of print by radio and television and because of the universal "political" legitimacy of Nationality, common language comes to play an ancillary role. The three stages are, in thumbnail sketch, late 18th to early 19th century American nationalisms claiming basically the same regions covered by British, Spanish or Portuguese colonial administrative units; 19th century Statist/dynastic "official nationalisms," in which pre-National States more-or-less consciously reshaped themselves to cover existing, or create plausible, linguistic/National boundaries; and post-World War I/League of Nations "last wave" nationalisms which adopt nationalism essentially as a narrowly "ideological" tool.

In the first stage, that of nationalism in the Americas, we notice several features which allowed for an imagined common community. Preceding, but supposed by, all the specific determinants of American nationalisms, however, was a conjunction of two phenomena in Europe during those same centuries in which America (and so much of the rest of the world) was being colonized. These were the simultaneous rise of print technology and of Capitalism-neither entirely unknown outside this time and place, but never before present in conjunction. It was these conjoined phenomena, as well as relatively independent "literary" innovations, which through a kind of cunning of Reason produced as an inadvertent consequence a widespread cultural belief in the simultaneity of diverse events.

Two written forms whose importance in the history of Nationalism Anderson emphasizes are also important for the analysis of the notion of simultenaity. These are the newspaper and the novel. The other forms of media, electronic, broadcast and so on, with which we are currently inundated fall broadly under the category of extensions of one or the other of these two printed forms. What is essential to each of these literary forms? The novel is the easier case, so let us start with it. Novels generally, if not necessarily, have contained in their literary form not only an implicit 
imagined audience who may recognize themselves as addressed — any literary form must have such an audience - but have also an implicit possibility of including the audience in the narrative itself. How may this be so? When we give the answer our modern reader may doubt that there is any literary form which does not also contain this possibility, but this first reaction will be too narrow in its cognitive specificity. The novel contains the implicit possibility of including the reader in its narrative because the novel takes place within a time structured by the possibility of simultaneity and succession - a structure of time which only became conceptually possible around the time that the first novels were written.

The distinction which Anderson utilizes between homogeneous linear time and messianic time is borrowed from Walter Benjamin. Time structured in homogeneous linear form, like that in a novel, always allows for the imaginary insertion of the reader into the text itself. Since the form of time of a novel allows for the temporal relation of all events, it allows for the reader to be inserted into this same temporal order. Perhaps there are some few novels written which do not allow this, but we should notice that even novels of "science-fiction" or "fantasy" generally place their narratives either in the distant past or the distant future, or perhaps in a distant place, so as still to allow the possibility of the reader existing somewhere within the temporal relations of the novel, even if at a remove from the concrete events. Even those few novels which may rule out a literal placement of the reader within the narrative (or in an extended version thereof) give conceptual explication of the homogeneous, linear time which is a condition of "national imagination."

With Anderson's remarks about newspapers we can see most clearly the relationship between homogeneous, linear time and imagined national communities. Insofar as time is homogeneous, every reader can be placed in the (limited) relationship of simultaneity under the emblem of the date at the top of the paper. A community of newspaper readers is imagined in part on the basis of the reality that a particular group of people will be reading this same newspaper; and partially on the already "imaginary" fact that this news is news for a particular imagined community rather than for other any other human beings.

A conception of homogeneous time allows both for the direct conceptualization of the "real" fact that readership of newspapers is simultaneous and limited and of the "imaginary" fact that the "news" is simultaneously newsworthy for all the imagined readership. As we have mentioned, the "facts" about newspaper reading repeat at both a "real" and an "imaginary" level the imaginary location of a reader within the narrative of a novel. Of course, the structure of homogeneous time, and of the imaginable communities which depend upon them, does not necessitate that imagined communities be national communities, but it at least opens that possibility to emerge from more narrowly "political" interests-in just the manner described in Anderson's book.

Let us return to our accusation that Anderson takes the pretensions of nationalists too seriously-or better, takes the reification of imagined nationality as an accomplished act rather than a constant, uneasy process. Anderson presents two data which he claims show the inconsistency of the linking of nationalism with racism. The first,

In an age when it is so common for progressive, cosmopolitan intellectuals (particularly in Europe?) to insist on the near-pathological character of nationalism, its roots in fear and hatred of the Other, and its affinities with racism, it is useful to remind ourselves that nations inspire love, and often profoundly selfsacrificing love. . . One the other hand, how truly rare it is to find analogous nationalist products expressing fear and loathing. [129] 
In other words, argues Anderson, racism (loathing of the Other) is concerned with hatred, and nationalism with love - so therefore they are different. Second, since nationalism is concerned with one's own nation in opposition (moral, military or ideological) to other nations, it must be different from racism which manifests itself 'not across national boundaries, but within them'; whose purpose is, 'not so much foreign wars as domestic repression and domination.' [136]

\section{Conclusion: Returning to "National" Subjects}

What is wrong with the arguments against connecting racism and nationalism which Anderson makes? Most broadly, Anderson fails to understand the basic Freudian point that the self is divided and contradictory. If, for example, nationalism is central to subjectivity, and the conscious form of nationalism is love of country, that simply does not imply that there is not simultaneously-and essentially - an unconscious basis for nationalism in hatred and loathing (i.e. racism). Of course, merely pointing out that many processes are unconscious does not in itself show that the unconscious desire of which nationalism is the conscious expression is one of hatred and loathing. However, when we realize that the "Nation" loved by nationalists is not an object with a coherent identity, but is a teeming mass of contradictions and impossibilities, we begin to understand the psychic imperative for exclusion of alterity which is contained at the heart of the "love." To repeat and expand this critique at a deeper level, we may point out that where Anderson writes throughout his book of an "imaginary" identification of a Subject with a Nation, what is really central in the relation between Subject and Nation is a "symbolic" identification. Although Anderson does not use his word 'imaginary' in a specifically Lacanian sense, his problem is that his meaning turns out to concord exactly with the Lacanian meaning of 'imaginary', as opposed to with the Lacanian 'symbolic'.

Žižek asks,

[W]hy precisely is this difference between how we see ourselves and the point from which we are being observed the difference between imaginary and symbolic? [108]

He answers,

In a first approach, we could say that in imaginary identification we imitate the other at the level of resemblance-we identify ourselves with the image of the other inasmuch as we are "like him," while in symbolic identification we identify ourselves with the other precisely at a point at which he is inimitable, at the point which eludes resemblance. [109]

Put in terms of nationalist "love:" if this "love" were an imaginary identification it would really rest on a wish to be like the National ideal-like the sort of nationalized subject created in Anderson's accomplished narrative; but since it is, instead, primarily a symbolic identification it rests on a wish to be seen by the "Nation" as having the proper National character. However, there is no "truth" to the "National character," nothing empirically to emulate; all there is is an almost infinite diversity of persons and several systems of schisms between antagonistically divided societal groups. Of course, these societal groups themselves are composed of diversity and antagonism (the proletariat, for example, is unified in nothing besides their opposition to the bourgeoisie). 
Since our "love" of Nation is actually an identification with the very position from which "the Nation" views us ("how we appear in the eyes of the nation"), it is always an unfulfilled love, marked by a blockage. In order to deny this blockage within need (i.e. desire through the lens of an identification with that whose desire our desire is the desire to fulfill), the blockage is projected on to an object of alterity which is fantasized as responsible for the blockage. We might say: as in ontogeny, so in phylogeny; just as psychoanalysis finds a particular site which condenses an individual's failure of subjectivation, every National subject's failure to achieve national-identity is condensed onto the racial Other. Our relation to that fantastic object which blocks the fulfillment of our love of Nation is inevitably one of hatred and loathing. It may well be, as Anderson claims, that the relationship to Nation within nationalism is one of love, but this love like so many others is an unstable accomplishment of a repressive psychic function-a function whose transferal side effect is a loathing of alterity.

Anderson's second objection vanishes also, under the reading we have given in the above paragraphs. Nationalism as a consciously articulable state of subjectivity is indeed directed against extra-national entities, and racism thusly against intra-national entities; but at the unconscious level which unites these two functions of subjectivity, the simple distinction vanishes. If racism is intranational that is simply because an intra-national Symbolic exclusion must have already taken place before "the Nation" as an entity opposable to other nations can exist. Racism and nationalism are related precisely in that racism is the prop needed to maintain an illusory nationalist subjectivity. 


\section{Bibliography}

Anderson, B. 1983. Imagined Communities: Reflections on the Origin and Spread of Nationalism. London: Verso.

Balibar, E. and Wallerstein, I. 1991. Race, Nation, Class: Ambiguous Identities. Translation of Etienne Balibar by Chris Turner. London, New York: Verso.

Balibar, E. 1991. "Es Gibt Keinen Staat in Europa: Racism and Politics in Europe Today." New Left Review 186, March/April

Benjamin W. 1968. Illuminations: Essays and Reflections. Edited and with an Introduction by Hannah Arendt. Translated by Harry Zohn. New York: Schocken Books.

Laclau, E. and Chantal Mouffe. 1985. Hegemony \& Socialist Strategy: Towards a Radical Democratic Politics. London: Verso.

Žižek ,S. 1989. The Sublime Object of Ideology. London, New York: Verso. 